\title{
X-linked and cellular IAPs modulate the stability of C-RAF kinase and cell motility
}

Taner Dogan, Gregory S. Harms, Mirko Hekman, Christiaan Karreman, Tripat Kaur Oberoi, Emad S. Alnemri, Ulf R. Rapp and Krishnaraj Rajalingam

Nature Cell Biol. 10, 1447-1455 (2008); published online 16 November 2008; corrected after print 24 November 2008;

In the version of this article initially published, the label c-IAP-1 in Figure $1 \mathrm{~d}$ was duplicated for both of the lower lines. The corrected panel displaying the omitted c-IAP-2 label is shown below. In the list of addresses, the affiliation for M.H., C.K. and U.R.R. should be Bayerishes Krebsforschungszentrum, MSZ, University of Wuerzburg, Germany. These errors have also been corrected in the HTML and PDF versions of the article.

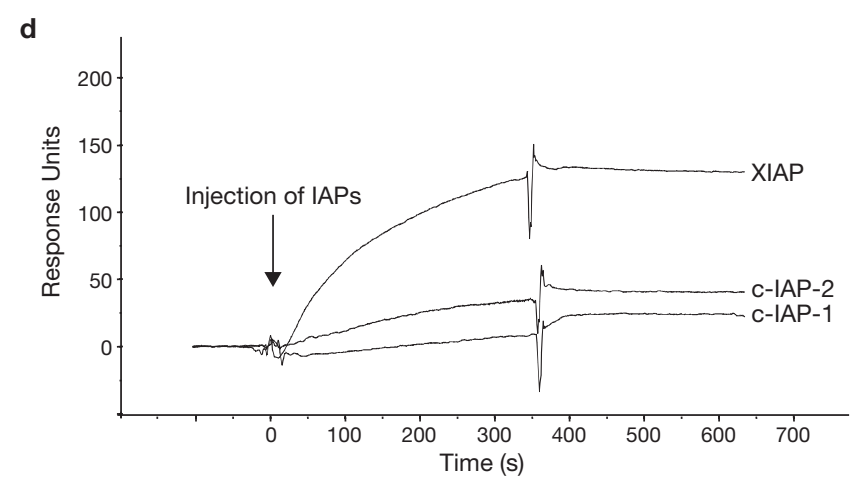

